\title{
SISTEMA INTEGRADO DE PRODUÇÃO DE FRANGO DE CORTE NA REGIÃO DO PARAGUAÇU
}

\author{
João Paulo Pereira da Cruz
}

Economista/Universidade Estadual de Feira de Santana/UEFS/BA

Paulojp.cruz@hotmail.com

\section{Telma Teixeira}

Economista. Dra. Engenharia Civil/Universidade Estadual de Feira de Santana/UEFS/BA telma@uefs.br

\section{Frank Pavan}

Advogado. Dr. Engenharia Civil/ISECENSA/RJ

frankpavan@coc.ufrj.br

\section{RESUMO}

Atualmente o Brasil é o maior exportador de carne de frango, destacando-se ainda como $3^{\circ}$ maior produtor mundial. A eficiência produtiva da atividade é garantida por meio do sistema integrado de produção que se traduz numa parceria entre a empresa (integradora) e pequenos produtores locais (integrados). Nos municípios da região do Paraguaçu (Conceição da Feira, São Gonçalo dos Campos e Feira de Santana) o modelo é adotado por 3 grandes empresas que dominam a produção local e estadual (Gujão, Avigro e JBS). No presente trabalho, por meio de entrevistas, foram coletadas informações para avaliação desse sistema segundo a ótica de ambos os parceiros. Os resultados evidenciam que embora haja satisfação com o modelo, os integrados da Avigro e JBS revelam alguns problemas na parceria.

Palavras-chave: Frango de Corte; Sistema Integrado; Região do Paraguaçu.

\begin{abstract}
Currently Brazil is the largest exporter of chicken meat, highlighting even as $3^{\text {rd }}$ world's largest producer. The productive efficiency of the activity is ensured by the integrated production system, which results in a partnership between the company (integrator) and small local producers (integrated). In the cities of Paraguaçu region (Conceição da Feira, São Gonçalo dos Campos and Feira de Santana) the model is adopted by 3 large companies that dominate local and state production (Gujão, Avigro and JBS). In this work, based on interviews, information was collected for evaluation of this system from the viewpoint of both partners. The results show that although there is satisfaction with the model, the integrated of Avigro and JBS reveal some problems in partnership.
\end{abstract}

Keywords: Broiler Production; Integrated system; Paraguaçu region. 


\section{INTRODUÇÃO}

A produção de frango de corte no Brasil ganhou destaque a partir dos anos 80 quando o país alcançou a segunda posição nas exportações mundiais. A liderança no ranking foi assumida em 2005, mantendo-se até os dias atuais. Na produção, o país ocupa a terceira posição, atrás apenas dos Estados Unidos e China.

A agroindústria de frango de corte possibilitou uma nova perspectiva a avicultura brasileira através da dinamização do consumo de carnes e diversificação das exportações, permitindo a comercialização em larga escala para diversos países. Além disso, o elevado consumo interno que representa mais de $65 \%$ da produção traz perspectivas de maior crescimento favorecido pelos preços comparativamente mais atrativos e preferência do consumidor por carnes brancas. Adicionalmente, o rígido controle sanitário exigido pelas exportações asseguram maior confiabilidade ao consumidor.

Na região do Paraguaçu, situada no agreste baiano e formada pelos municípios de Feira de Santana, São Gonçalo dos Campos e Conceição da Feira, essa atividade tem causado mudanças extraordinárias na vida dos pequenos produtores rurais. Terras que antes proporcionavam apenas uma renda mínima para subsistência com plantio de lavouras ocupando amplas áreas, foram substituídas por galpões de aproximadamente $1.800 \mathrm{~m} 2$ para a produção de frango que exige a dedicação exclusiva do produtor integrado.

A transformação da Região ocorreu a partir de 2002 com a implantação do Sistema Integrado (SI) de produção de frango, replicando um modelo que já apresentava sucesso nos estados do sul e sudeste do país onde estão os maiores produtores nacionais. O Sistema, baseado em uma parceria entre o frigorífico industrial e o pequeno avicultor reduziu os custos de produção para ambos, garantindo renda e segurança ao homem do campo inserido na atividade, entre outros elementos. Apesar de ainda haverem produtores independentes, o mercado e produção local é controlado pelas empresas Gujão Alimentos, Avigro - Avícola Agroindustrial Ltda e JBS.

O modelo de produção adotado pelas empresas é o objeto de estudo do presente trabalho que tem por objetivo caracterizar e analisar o sistema de integração adotado na produção de frango de corte nos municípios da Região do Paraguaçu a partir da ótica dos grandes frigoríficos e dos produtores integrados. As informações obtidas através de entrevistas com representantes das empresas e 40 de seus parceiros revelam que o modelo base de integração apresenta distinções contratuais relacionadas aos requisitos para ingresso e manutenção no sistema, a qualidade dos pintos de um dia fornecidos e as taxas cobradas para manutenção, entre outros elementos.

Verifica-se que embora o modelo de produção seja avaliado positivamente pelos integrados e empresas integradoras, a satisfação com a parceria estabelecida é posta em questão. Apenas os produtores vinculados à Gujão Alimentos não apresentam críticas negativas em relação à integradora, ao tempo em que mais da metade dos integrados da JBS estariam dispostos a mudar de parceiro.

Nas seções que se seguem são apresentados os procedimentos metodológicos adotados no desenvolvimento deste trabalho e o panorama geral da atividade de produção de frango de corte no Brasil e nos municípios do Paraguaçu. Dando continuidade, os resultados das entrevistas são sistematizados e discutidos, relatando as informações quanto ao sistema de integração adotado pelas empresas a partir da percepção destas e de seus integrados. Algumas considerações finais encerram o trabalho. 


\section{METODOLOGIA}

O histórico e situação atual da avicultura nacional, bem como o desenvolvimento específico da indústria de frango de corte toma como base relatórios e estudos da Associação Brasileira de Proteína Animal (ABPA). A produção de frango de corte é então caracterizada no Brasil e nos municípios da região do Paraguaçu a partir de dados da Pesquisa Pecuária Municipal (PPM) do Instituto Brasileiro de Geografia e Estatística (IBGE). A base para informações acerca do plantel considera a categoria 'galináceos' informada pela PPM, composta pelos rebanhos de galinhas, galos, frangos, frangas, pintos e pintainhas, sendo as estatísticas da categoria 'galinha' também divulgadas separadamente. A eliminação do rebanho de galinhas do quantitativo total leva a uma correta aproximação do plantel específico de frango de corte dos municípios, visto que embora aí possa estar também presente outras espécies, estas são consideradas de pouca relevância na atividade, não comprometendo as análises (IBGE/GEPEC, 2013).

O Sistema Integrado adotado pelas grandes empresas integradoras que atuam nos municípios selecionados foi verificado em suas características específicas utilizando o método de levantamento com base em entrevistas estruturadas de questões abertas realizadas no mês de novembro de 2014. Em relação aos representantes dos frigoríficos as entrevistas foram conduzidas no intuito de obter detalhamento acerca do processo de integração da empresa, os procedimentos para ingresso, as exigências para manutenção de contrato e a estrutura existente.

Através de formulário, também com perguntas abertas estruturadas, foram coletadas informações junto aos pequenos produtores integrados. 40 produtores foram questionados quanto a mão de obra empregada no processo, se familiar e/ou terceirizada, a rentabilidade, as vantagens e/ou desvantagens da integração e a satisfação em relação a integradora.

\section{PRODUÇÃO DE FRANGO DE CORTE}

\subsection{Panorama Nacional do Setor}

No Brasil a produção de frango de corte consolidou-se nos anos 50 e 60 impulsionada por técnicas de produção mais modernas, aprimoramento das rações para melhor dieta dos animais, desenvolvimento de novas vacinas e melhoria genética do plantel nacional por conta da importação de uma nova linhagem dos EUA. Apesar do elevado crescimento da produção, até 1960 os animais eram criados soltos, sem cuidados alimentares e abatidos com até 80 dias de idade. As grandes granjas eram então responsáveis pela criação dos próprios animais ou compra de terceiros (COSTA, 2011).

O modelo de produção se altera a partir dos anos 60 com a implantação do Sistema Integrado (SI). Originário nos EUA, o SI foi implantado no Brasil na década de $60 \mathrm{em}$ Santa Catarina, fruto de uma parceria que envolvia uma cooperativa então em dificuldades e o empresário fundador da Sadia o Sr. Atílio Fontana (PINAZZA e LUANDOS, 2000). De uma forma geral, o Sistema Integrado consiste em uma parceria entre uma empresa de grande porte (integrador) e um pequeno latifundiário (integrado). Este último se responsabiliza pelo fornecimento do espaço para instalação dos galpões, manejo dos pintos de um dia para engorda, água, energia elétrica, lonas para manutenção da temperatura dos pintos e a mão de obra. Em contrapartida a empresa fornece o suporte técnico sanitário, a ração, os medicamentos, os pintos de um dia, as vacinas e o transporte dos frangos para o abatedouro. Adicionalmente toda parte logística é de responsabilidade da empresa, desde a comercialização à distribuição dos frangos para o mercado consumidor.

A expansão do SI na agroindústria aproveitou a estrutura fundiária constituída de pequenas propriedades que se adequou a característica do sistema de parceria utilizando basicamente mão de obra familiar. Os pintos de um dia são selecionados e vacinados nas primeiras horas de vida; geralmente pesam em média $50 \mathrm{~g}$ e nos primeiros 12 dias devem ser mantidos em uma temperatura média de $28^{\circ}$ a $32^{\circ}$ graus. Além disso, com uso de rações balanceadas os pintos deve ganhar $58 \mathrm{~g}$ gramas de peso por dia. A empresa através do corpo técnico realiza a cada 7 dias a pesagem dos pintos para verificar se o ganho de peso está dentro da meta.

Persp. Online: exatas \& eng., Campos dos Goytacazes, 16 (06) 1 - 11 - 2016 
A parceria com os pequenos produtores juntamente com a escolha de novas técnicas de produção possibilitou o manejo do frango com mais qualidade, o fornecimento de assistência técnica e a redução da convenção alimentar, garantindo assim a produção em grande escala (VOILÀ e TRICHES, 2013).

Segundo afirma Costa (2011), o modelo de integração gera ganhos para ambos os parceiros envolvidos. A empresa beneficia-se da redução dos custos inerentes a produção própria (terras, equipamentos, mão de obra etc.), obtendo matéria prima adequada em quantidade e qualidade e em ritmo adaptado a dinâmica do processo produtivo e do mercado. Por sua vez, os avicultores, com autonomia gerencial sobre sua atividade, garantem o escoamento do produto e consequente estabilidade na geração de renda, ao que se somam as maiores facilidades de crédito e menor custo de incorporação de inovações, decorrentes dos treinamentos fornecidos pelas empresas. A eficiência do Sistema Integrado garantiu assim que o modelo se tornasse o mais adotado no desenvolvimento das atividades no país gerando em torno de 4,5 milhões de postos de trabalho diretos e indiretos com um produto que atende a padrões internacionais de qualidade. Embora ainda sejam verificados produtores independentes em algumas regiões do país, o modelo integrado predomina na avicultura e as taxas de crescimento registradas são aproximadamente 3 vezes superiores aos independentes (COSTA, 2011).

A produção brasileira se concentra no interior nas regiões Sul e Sudeste sendo Paraná, Santa Catarina e Rio Grande Sul os maiores produtores com percentuais de abate de 32,26\%, 16,96\% e 14,24\% registrados em 2014 (ABPA, 2015). Juntos esses Estados são responsáveis por mais de 70\% das exportações nacionais de carne de frango.

Desde a implantação do SI, o maior volume de produção de frango de corte brasileiro foi registrado no ano de 2011, com produção de 13.058 milhões de toneladas, fato que levou o país a figurar entre os três maiores produtores do mundo, perdendo apenas para a EUA e China respectivamente primeiro e segundo colocados. Com uma produção de 12.691 mil toneladas registrada em 2014 o Brasil mantêm a terceira posição entre os produtores, embora lidere as exportações de carne (ABPA, 2015).

Os dados revelam que a adoção do modelo integrado de produção gerou uma demarcação de amplo significado na trajetória da avicultura brasileira. Associada ao crescimento dos índices de produtividade e renda, inserção ampliada e consolidada do país no mercado internacional, geração de emprego e renda e desenvolvimento técnico e científico no setor, destaca-se ainda a maior profissionalização do avicultor que diante das condições favoráveis apresentadas pela atividade opta por fixar-se no campo. Dessa forma, o SI pode ser identificado como um modelo promotor da interiorização produtiva e desenvolvimento regional, fato que tem se verificado também na Região do Paraguaçu, conforme será tratado na próxima seção.

\subsection{FRANGO DE CORTE NA REGIÃO DO PARAGUAÇU}

A Região do Paraguaçu esta localizada no centro norte da Bahia, abrangendo os municípios de Feira de Santana, Conceição da Feira e São Gonçalo dos Campos que totalizam 1.801,61 km2 com uma população registrada pelo Censo Demográfico de 610.316 habitantes (CENSO DEMOGRÁFICO 2010, 2011). Em seu conjunto a Região apresenta elevada densidade demográfica (339 habitantes/km2) e população essencialmente urbana (88,52\%), contudo a distribuição territorial e populacional é significativamente heterogênea entre os municípios.

- Feira de Santana é o maior município dessa região, com área territorial de 1.337,99 km2 e população de 556.642 habitantes. Com uma densidade demográfica superior a 410 habitantes $/ \mathrm{km} 2$, a população do município de Feira é predominantemente urbana $(91,73 \%)$.

- São Gonçalo dos Campos embora seja o segundo maior município da região tem apenas 300,73 $\mathrm{km} 2$ representando menos de $25 \%$ do território feirense. Com densidade demográfica também elevada (110,67 habitantes $/ \mathrm{km} 2)$, ao contrário dos demais municípios da Região tem concentração populacional na área rural $(64,43 \%)$.

Persp. Online: exatas \& eng., Campos dos Goytacazes, 16 (06) 1-11 - 2016 
- Conceição da Feira, o menor e menos populoso município da região é, paradoxalmente o maior produtor de frango. Sua área territorial $(162.883 \mathrm{~km} 2)$ é quase a metade de São Gonçalo dos Campos e pouco mais de $10 \%$ da área de Feira de Santana. Dados do IBGE informam que no ano censitário de 2010 a população do município era de 20.391 habitantes com densidade demográfica de $125,18 \mathrm{hab} . / \mathrm{km} 2$ concentrada na área urbana.

A produção de frango de corte na região teve início no município de Conceição da Feira com a implantação das empresas Gujão Alimentos e Avigro Avícola, voltadas a princípio para o comércio local de animais vivos, não havendo então frigorífico industrial na região. A Pesquisa Pecuária Municipal do IBGE (PPM, 2015) informa que a avicultura da região, exceto galinhas, era composta de pouco mais de 6 milhões de cabeças de dezembro de 2014, representando aproximadamente $25 \%$ do rebanho do Estado da Bahia.

O primeiro frigorífico industrial construído pela Avigro em 2001, a implantação da Avipal e a posterior construção do segundo frigorífico favoreceu a produção de frango em larga escala, possibilitando o crescimento do setor. O sistema de abate então implantado, hoje também presente na Gujão, tem tecnologia de ponta baseada no sistema de 'nória' (transportador aéreo ou linha móvel) que conduz o frango através de uma esteira suspensa para o reservatório de água, onde o animal é impactado com uma corrente elétrica que causa atordoamento, facilitando assim o posterior sangramento (manual ou mecânico) e depenagem automática. Através desse processo torna-se possível o abate de aproximadamente 150 mil aves por dia (COTTA, 2012).

Entre o final da década de 90 e início do novo século o rebanho do conjunto dos municípios era de aproximadamente 4 milhões de cabeças, fortemente concentrado em Conceição da Feira que abrigava mais de $85 \%$ do plantel. O surgimento da Avigro, Gujão, Carolina e Tambaú entre outros frigoríficos a partir de 2001 não apenas proporcionou elevação da produção, mas também desconcentração do plantel, privilegiando São Gonçalo dos Campos (Figura 1).

Poucos anos após a sua implantação em escala industrial e no modelo de sistema integrado, a avicultura na região do Paraguaçu sofre seu primeiro choque. A suspeita de gripe aviária no continente asiático em 2005, confirmada em 2006, reduziu o consumo mundial levando a queda das exportações e produção brasileiras, refletindo o medo de transmissão da influenza (vírus N1h1) para o humano através do consumo da carne de frango (TAVARES e RIBEIRO, 2007). Na ocasião, Conceição da Feira que abrigava o maior plantel da região, sofreu o maior impacto entre os municípios do Paraguaçu; 3,1 milhões de cabeças em 2005 após a crise da gripe foram reduzidas a menos de 1 milhão em 2007 quando já se iniciava a recuperação do setor.

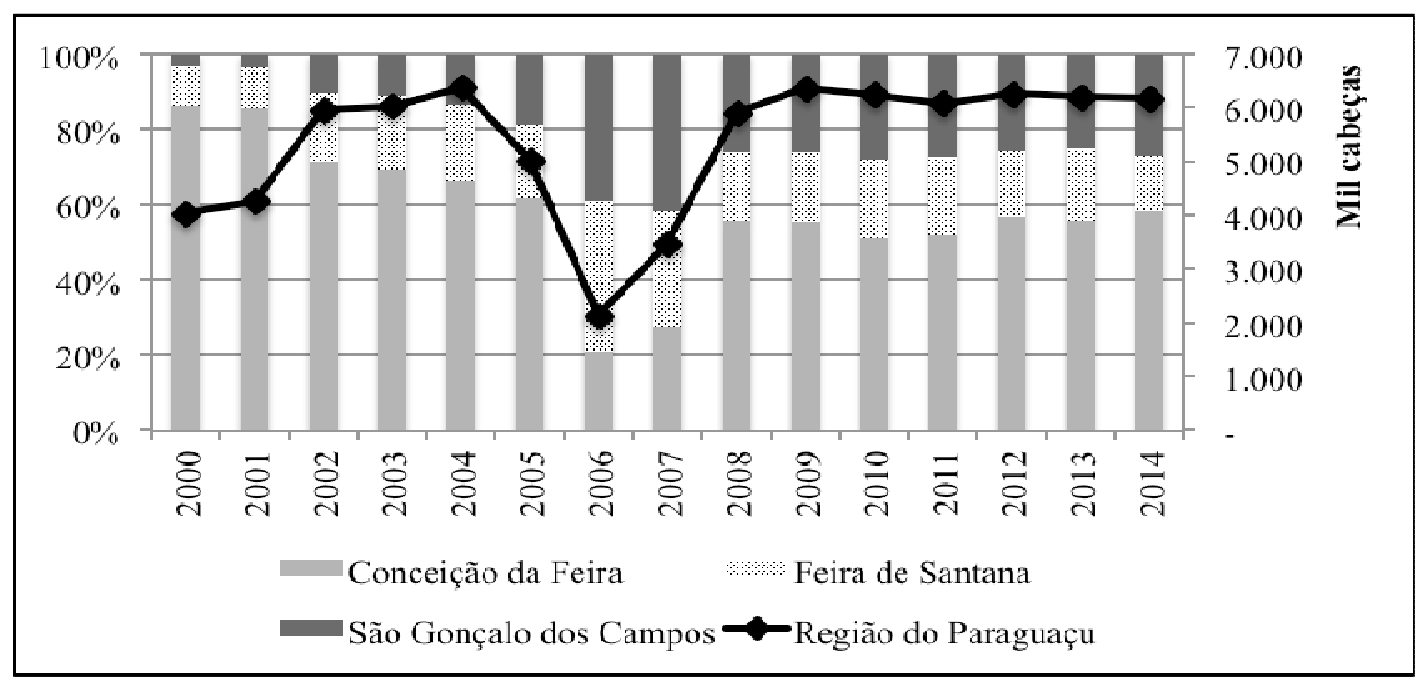

Figura 1 - Rebanho Avícola nos Municípios da Região do Paraguaçu: quantitativo total de cabeças e distribuição percentual. 2000-2014. Fonte: Pesquisa Pecuária Municipal- PPM, 2015 
A recuperação da atividade consolidou-se em 2008 com maior participação do município de São Gonçalo dos Campos. A partir desse ano o plantel do conjunto dos municípios do Paraguaçu atinge a casa dos 6 milhões de cabeças, mantendo-se nesse patamar até os dias atuais.

A produção de frango de corte na Região do Paraguaçu e também no Estado da Bahia é controlada por 3 grandes empresas do setor que utilizam o modelo de Sistema Integrado de produção, responsável pelo crescimento dos indicadores de produtividade a partir de 2002. São elas:

- Gujão Alimentos: empresa local fundada em 1984 com um plantel de 3.300 frangos então comercializados vivos. Visando o crescimento e destaque no Estado, em 1991 a Gujão adquiriu outras três granjas e começou a investir em técnicas inovadoras de produção (GUJÃO ALIMENTOS, 2015). Em entrevista o representante da empresa informou que sua estrutura conta com incubatório próprio localizado no Município de Água Fria (BA), com capacidade de fornecimento mensal de dois milhões de pintos de um dia, tornando a empresa independente para oferecer aos seus integrados os pintos de melhor qualidade. A Gujão tem também uma fábrica de ração localizada no município de Conceição da Feira desde 1984, onde também está localizado seu centro administrativo e logístico denominado Nova Granja que fornece apoio técnico nas áreas de saúde, nutrição e genética aos mais de 400 integrados;

- Avigro Avícola Agroindustrial Ltda: implantada nos anos 70, a empresa teve início com a criação de 200 pintos na granja Santa Elena. O crescimento e sucesso do empreendimento fez surgir a Avigro Avícola Agroindustrial Ltda em 1987. Seu núcleo de engorda denominado Nova Esperança, atual Limoeiro I, foi construído em 2001. Nele localiza-se o abatedouro industrial e o frigorífico da empresa. No início do processo a empresa era responsável pelo setor de engorda dos pintos de um dia sob os cuidados dos funcionários da empresa, com vínculo trabalhista. Visando reduzir custos e aumentar a produtividade, a empresa passou a arrendar os galpões a produtores independentes. Esse sistema de arrendamento deu continuidade com a implantação da integralização, uma vez que a indústria incorpora uma taxa de arrendamento aos custos do lote (período de 40 a 50 dias de engorda dos frangos) (CONCEIÇÃO, 2007). Localizada no município de Conceição da Feira, a Avigro é a terceira colocada entre as grandes integradoras da Região do Paraguaçu com abate diário de 50 mil aves;

- JBS (ex-Avipal): A Avipal Nordeste S/A fazia parte do Grupo Avipal com sede em Porto Alegre, que teve suas atividades iniciadas em 1959. A empresa instalou-se na Bahia em 1998, implantando estrutura de uma empresa de grande porte, com a construção do frigorífico, abatedouro e fábrica de ração e investimento de R $\$ 138$ milhões, tendo desenvolvido suas atividades nos municípios de São Gonçalo dos Campos e Feira de Santana. O SI foi implantado em 2002, firmando parceria com mais de 500 integrados e gerando em torno de 1250 empregos diretos. Segundo Conceição (2007) a empresa representa mais de $40 \%$ da produção de frango de corte da região, com capacidade de abate de $150 \mathrm{mil}$ aves/dia, fato que modificou o padrão da atividade na região, inserindo a Bahia no cenário avicultor nacional. A partir de 2007 a Avipal passou por diversas modificações societárias e após fusões e incorporações foi comprada pela JBS que é a segunda maior empresa exportadora de carne de frango do país (ABPA, 2015).

Embora empreguem o modelo de integração em parceria com os avicultores dos municípios, os modelos contratuais das integradoras diferenciam-se em termos específicos que afetam a rentabilidade e segurança dos integrados, ao tempo em que interferem positiva e negativamente na opinião dos produtores não integrados. Estas distinções e semelhanças são o objeto de discussão nas próximas seções.

\section{RESULTADOS E DISCUSSÃO}

\subsection{O Sistema de integração pela ótica das empresas}

O contato estabelecido com as empresas buscou informações sobre a condução do processo de integração (exigências e acompanhamento), identificando a visão da agroindústria acerca das vantagens e desvantagens do modelo para o produtor, para a empresa e para a economia local.

Persp. Online: exatas \& eng., Campos dos Goytacazes, 16 (06) 1-11 - 2016 
A partir das entrevistas com os representantes das empresas foi possível totalizar os dados relacionados a estrutura de funcionamento do sistema integrado de produção nos municípios da Região do Paraguaçu. Juntas, a Gujão, Avigro e JBS são responsáveis pela geração de 2.400 empregos diretos e integram 732 pequenos produtores (Tabela 1).

A Gujão é claramente a maior empresa da região, fato certamente favorecido pela sua origem local. Contudo, deve ser observado que a JBS é a maior processadora mundial de frangos, com capacidade instalada para processamento diário de até 12 milhões de aves no conjunto das unidades dos 4 países onde atua. Nesse sentido, o bom desempenho do sistema no Estado e sua proximidade com o mercado consumidor norte-nordeste pode estimular ainda mais o crescimento da atividade e alterar a distribuição de participação na produção então verificada.

No que corresponde a geração de emprego, os dados revelam que a Avigro é a empresa de maior benefício para o local. A relação empregos diretos e integrados nesta empresa é de 6,2, significativamente superior a Gujão $(2,5)$ e JBS $(3,6)$. Esses números embora aparentemente positivos podem significar uma estrutura administrativa mais robusta e menos eficiente e/ou uma maior capacidade de apoio ao produtor integrado. Contudo, essa segunda hipótese é descartada quando verifica-se a impressão negativa dos integrados quanto aos técnicos da empresa.

Tabela 1: Dados Gerais das Grandes Empresas Integradoras da Região do Paraguaçu

\begin{tabular}{lccc}
\hline \multicolumn{1}{c}{ Dados gerais } & Gujão & Avigro & JBS \\
\hline $\mathrm{N}^{\text {o }}$ integrados ativos & 402 & 80 & 250 \\
$\mathrm{~N}^{\mathrm{o}}$ núcleos de engorda & 413 & 25 & 250 \\
Capacidade de alojamento/semana & 560 & 300 & 400 \\
Produção da fábrica de ração (ton/semana) & 3 & 2,5 & 3 \\
$\mathrm{~N}^{\mathbf{o}}$ Empregos Diretos & 1005 & 500 & 890 \\
\hline
\end{tabular}

Na visão das empresas, o modelo de produção através do sistema integrado, embora motivado por razões distintas e caracterizado a partir de elementos diversos, é defendido como mais eficiente e de menor custo para as integradoras e mais satisfatório para os integrados. Estas constatações, bem como as percepções individuais da Gujão Alimentos, Avigro e JBS sobre o sistema são detalhadas a seguir.

- Gujão Alimentos: O Sistema Integrado foi implantado na empresa com o claro objetivo de terceirização das atividades de criação de aves, reduzindo custos com a manutenção dos padrões de qualidade através do acompanhamento dos parceiros/integrados, sendo estes remunerados por um fator de produção. O entrevistado afirmou que o SI viabiliza uma produção mais eficiente ao tempo em que permite a fixação do homem no campo, permitindo que os pequenos produtores, com baixo nível de escolaridade e capacitação técnica, obtenham uma renda superior ao que seria possível no mercado independente. Além das vantagens diretas ao parceiro/integrado, o modelo dinamiza a economia local através da geração de postos de trabalho de forma significativa, criando empregos nos setores de venda, transporte, administração etc.

No processo de adesão ao modelo de integração exige-se que o pequeno produtor possua área rural situada num raio de $80 \mathrm{~km}$ em relação à sede da empresa com aviário equipado, energia elétrica, água em abundância e mão de obra para execução das atividades. O contrato assinado por 12 meses, passível de renovação, é avaliado com base nos resultados técnicos e econômicos do integrados.

Para o entrevistado a avicultura industrial é uma atividade rentável, embora não apresente lucros acima da média. O elemento de maior impacto nos custos relaciona-se a distância dos grãos para a ração dos anima vindos do oeste baiano, sendo tal desvantagem compensada pela proximidade do mercado consumidor, pelo menor volume de capital imobilizado nas propriedades e pelo baixo custo da mão de obra, com a qual não se mantêm vínculo trabalhista. 
Nos planos da empresa não está prevista a expansão da produção. Os elevados custos iniciais e o lucro comparativamente pequeno em relação a outras carnes desestimula a construção de novos aviários e consequente aumento da capacidade produtiva;

- Avigro - Avícola Agroindustrial: Na percepção do representante da Avigro o SI é um dos grandes responsáveis pelo crescimento da produção de carne de frango no país e na região estudada. Fatores como segurança na remuneração, não vulnerabilidade em relação as oscilações de mercado e isenção de riscos de comercialização são claras vantagens para o pequeno produtor.

Os melhores resultados decorrem do estímulo a produtividade através da remuneração. O integrado tem seu ganho condicionado a sua eficiência produtiva e seu melhor desempenho traduz-se em menores custos também para a empresa integradora. A inserção como integrado na empresa baseiase em critérios de localização, estado de conservação das instalações e disponibilidade de água além de outros requisitos que não foram mencionados. Uma vez aceita a inscrição, o parceiro/integrado passa a ser orientado e assistido pelo corpo técnico da empresa e deve cumprir com todas as recomendações técnicas para que atinja, ao final da criação, a meta mínima de resultados pré-estabelecida.

A remuneração ocorre ao final do ciclo de criação, quando as aves são enviadas ao abatedouro para avaliação com base nos índices de mortalidade, conversão alimentar e ganho de peso. Estes índices revelam a eficiência produtiva do integrado e, consequentemente, tem impacto direto na sua remuneração. Na avaliação da empresa o consumo de carne de frango na Bahia é crescente, uma vez que até pouco tempo o Estado produzia apenas $30 \%$ da carne de frango que consumia. Diante disto, empresas da região sul e sudeste do país viram um mercado potencial para a implantação de suas empresas, trazendo a cultura da criação de frangos sob o regime de Integração;

- JBS: A JBS não apresentou disponibilidade para receber pessoalmente o entrevistador e o contato foi feito via telefone. $\mathrm{O}$ interlocutor identificado como um dos coordenadores da empresa apenas confirmou o número atual de integrados, informando que alguns pequenos produtores encontravam-se inativos por não cumprimento das exigências e baixo índice de produtividade. No sistema de avaliação o parceiro/integrado é classificado em níveis (A, B ou C) correspondentes ao seu desempenho e estrutura. $\mathrm{O}$ grupo $\mathrm{C}$ agrega os produtores inativos que na ocasião da entrevista totalizavam 250 parceiros. Chamando atenção para o fato de que este é também o quantitativo de integrados ativos, foram solicitados maiores detalhes quanto às exigências feitas pela empresa, contudo a questão não foi respondida.

\subsection{Pequenos produtores integrados: avaliação do modelo}

Foram entrevistados 40 pequenos produtores das empresas Gujão Alimentos (20), Avigro (8) e JBS (12). Na montagem do perfil destes verificou-se que mais de $70 \%$ dos entrevistados exercem a atividade de avicultor há mais de 5 anos, estando na Gujão Alimentos os recém ingressos (menos de 3 anos de atividade).

No que concerne a formação educacional, quase $50 \%$ dos produtores declararam ter completado apenas o nível fundamental, sendo que $31 \%$ alcançou apenas as primeiras séries desse nível. Destacam-se nesse quesito a Gujão Alimentos com o maior percentual de associados sem instrução e a JBS por ter os únicos integrados com nível superior completo entre os entrevistados.

Considerando que a jornada de trabalho do avicultor tem relação direta com a fase de crescimento do frango, também a mão de obra necessária sofre oscilações. Entre os integrados, todos são auxiliados em suas atividades com mão de obra adicional em caráter permanente (geralmente familiar) ou temporário. Dessa forma, aos empregos diretos criados pelas empresas integradoras podem ser também somados os postos de trabalho ocupados junto aos parceiros integrados, diretamente envolvidos na atividade. $\mathrm{Na}$ amostra pesquisada foram contabilizados 101 empregos permanentes e 30 temporários, estando $50 \%$ de cada faixa trabalhando junto a integrados da Gujão Alimentos.

A avaliação geral dos produtores em relação ao sistema apresenta algumas distinções quando comparadas as opiniões emitidas pelos representantes das empresas, sendo essas diferenças mais

Persp. Online: exatas \& eng., Campos dos Goytacazes, 16 (06) 1-11 - 2016 
destacadas na Avigro. Apesar disso a satisfação com a atividade e a remuneração obtida é quesito unânime entre os 40 integrados entrevistados. Relevante salientar que apenas a Gujão foi positivamente avaliada em todas as questões apresentadas.

As demais observações coletadas através das perguntas abertas foram sistematizadas no intuito de melhor caracterizar as distinções no modelo de integração de cada empresa-parceira. Essa síntese é apresentada na subseções que se seguem.

- Integrados da Gujão Alimentos: a fuga do desemprego e a possibilidade de uma renda assegurada foram os principais atrativos revelados pelos produtores para a integração. Os 20 entrevistados evidenciaram ter conhecimento quanto as exigências listadas pela integradora e acrescentaram ainda a necessidade de possuírem telas para evitar passarinhos e o impedimento de diversificar a criação ou aceitar outro contrato de forma paralela. Embora tenham revelado mais requisitos que aqueles listados pelo representante da empresa, os integrados definiram a relação como pouco exigente.

Os resultados financeiros positivos auferidos, pagos com pontualidade, são apontados como consequências também do apoio técnico da empresa integradora que se insere no processo para garantir a satisfação para ambos os parceiros. Os entrevistados ressaltaram ainda o bom relacionamento na parceria, a qualidade da ração e dos pintos fornecidos, além da competência da assistência técnica. Dessa forma, a ampla maioria dos integrados da Gujão Alimentos (90\%) declararam-se muito satisfeitos com a integração, afirmando que recusariam qualquer oferta para mudar de integradora;

- Integrados da Avígro: os 8 entrevistados informaram que o elemento motivador para a integração foi o desemprego, tendo sido conduzidos à empresa através de outros integrados. No processo de seleção, ao contrário do reportado pelo representante da empresa, os entrevistados informaram quem não há exigências para a integração.

Críticas negativas foram levantadas pelos integrados quanto a assistência da integradora. Os entrevistados mostraram-se insatisfeitos com o fornecimento de pintos de várias raças e a ração sem qualidade que interferem na produtividade. Adicionalmente o suporte técnico foi consenso quanto a sua ineficiência; os entrevistados informaram que a formação dos técnicos é insuficiente sendo o aprendizado adquirido em convívio com o integrado a despeito das taxas pagas à integradora pela manutenção e apoio. No período de realização das entrevistas os integrados informaram a ausência de veterinário para suporte as atividades, gerando preocupações quanto a enfermidades das aves que não pudessem ser resolvidas pelos técnicos.

Apesar das críticas, os entrevistados indicaram estarem satisfeitos com a integração. Certamente, tal posicionamento encontra suas bases na remuneração, afinal o resultado da produção é frequentemente positivo e na ocorrência de 'lote negativo' a empresa garante uma remuneração mínima de R\$ 800,00 (valores de novembro de 2014). Adicionalmente, os débitos não são automaticamente cobrados nos resultados positivos subsequentes, permitindo melhor planejamento financeiro do produtor;

- Integrados da JBS: a Avipal, atual JBS, como pioneira na implantação do sistema integrado de produção em grande escala na região em 2002 iniciou o processo de seleção de parceiros de forma diferenciada. Para apresentar o projeto de implantação do sistema a empresa organizou um seminário na câmara municipal de São Gonçalo dos Campos expondo então o funcionamento do modelo. Após o evento a empresa enviou técnicos para as pequenas propriedades agrícolas da região realizando as primeiras parcerias. $67 \%$ dos 12 entrevistados informaram que foram contatados pela empresa nesse processo e $95 \%$ informaram que ingressaram na atividade de criação de frango de corte através da integração.

As exigências para a parceria foram reveladas pelos integrados que assim como os parceiros da Gujão, demostraram amplo conhecimento dos requisitos: água em abundância na propriedade; energia elétrica; acesso fácil para o transporte; proibição de criar outros animais; proibição de acesso aos galpões para pessoas estranhas e; distância máxima de $60 \mathrm{~km}$ em relação à sede da empresa.

Os entrevistados não opinaram quanto a qualidade dos pintos e rações fornecidos, nem mesmo quanto a assistência técnica para manutenção da atividade, contudo verificou-se unanimidade

Persp. Online: exatas \& eng., Campos dos Goytacazes, 16 (06) 1-11 - 2016 
quanto a satisfação do modelo de produção por conta da renda auferida e da possibilidade de independência no exercício da atividade que não gera vínculo trabalhista. Paradoxalmente, apesar da satisfação declarada, $58 \%$ dos entrevistados declararam que estariam dispostos a mudar de parceiro integrador em razão do elevado grau de exigência da empresa e da relação conflituosa desta com os integrados.

\section{CONCLUSÕES}

A eficiência do sistema integrado de produção de frango para corte assegurou o bom desempenho do Brasil no mercado internacional, mantendo-o até os dias atuais como maior exportador mundial. Nos municípios da região do Paraguaçu, composta por Conceição da Feira, São Gonçalo dos Campos e Feira de Santana, esse modelo foi de fundamental importância para o pequeno produtor que através de treinamento e orientações teve acesso a inovações tecnológicas e produtivas que viabilizaram a produção em larga escala, melhorando a renda e fixando o homem no campo. A Gujão Alimentos, Avigro e JBS dominam a produção da região, sendo também de grande representatividade no Estado da Bahia e com amplas possibilidades de expansão considerando a demanda a ser suprida no norte-nordeste.

No presente trabalho, através de entrevistas com representantes das empresas, evidenciou-se que na percepção destas o Sistema Integrado permitiu a terceirização da produção e possibilitou redução de custos, ganhos de escala, aumento de produtividade e eficiência alimentar. Foram assim evitados, entre outros, custos com latifúndio e mão de obra que decorreriam da produção direta.

Também para os integrados o modelo pode ser considerado como vantajoso. Entrevistas conduzidas com parceiros das empresas citadas evidenciaram que a satisfação com a atividade, a renda gerada e a independência na operacionalização direta da produção são pontos comuns entre os entrevistados. Contudo, tal sentimento não se estende de forma uníssona para a relação com as empresas parceiras. A Gujão Alimentos é a única entre as integradoras positivamente avaliada pelos seus integrados, ao tempo em que por razões relacionadas a falta de apoio técnico, excesso de exigências ou problemas de comunicação a Avigro e JBS são negativamente citadas. É válido considerar que a Gujão Alimentos tem suas origens na própria região, do que resulta sua maior habilidade para tratar com especificidades relacionadas ao perfil sociocultural do produtor.

Pode-se então concluir que embora o modelo de produção integrada seja amplamente aceito por ambos os parceiros, a execução dos contratos, semelhantes em suas exigências, resultam em práticas distintas que impactam negativamente a satisfação do integrado. A ausência ou insuficiência de acompanhamento técnico competente prejudica a produção e o desempenho do setor que tem grande potencial de crescimento para atender a demanda do Estado e regiões próximas competindo com os grandes produtores do sul-sudeste. Cabe assim às empresas instaladas observarem as especificidades locais adequando-se as relações com os integrados com base no perfil social e cultural verificado. A desconcentração produtiva da atividade do eixo sul-sudeste, embora possa ser pautada em técnicas e/ou modelos de produção e organização similares não podem prescindir das características que definem a identidade local do homem do campo.

\section{REFERÊNCIAS}

ASSOCIAÇÃO BRASILEIRA DE PROTEÍNA ANIMAL - ABPA. Relatório Anual de Atividades 2015. Disponível em: http://abpa-br.com.br/files/RelatorioAnual_UBABEF_2015_DIGITAL.pdf. Acesso em 10 jan 2016.

CENSO DEMOGRÁFICO 2010. Rio de Janeiro: IBGE, 2011. Disponível em: ftp://ftp.ibge.gov.br/Censos/Censo_Demografico_2010/.Acesso em: 10 jan. 2016.

CONCEIÇÃO, Edney. Territorialidade da avicultura de corte na Bahia: o sistema integrado de produção avícola nos municípios de São Gonçalo dos Campos e Conceição da Feira - BA. 2007. 303

Persp. Online: exatas \& eng., Campos dos Goytacazes, 16 (06) 1-11 - 2016 
f. Dissertação (Mestrado) - Curso de Geografia, Instituto de Geociências, Universidade Federal da Bahia, Salvador, 2007. Disponível em: <http://www.posgeo.ufba.br/dissertaçoes/Dissertação - Edney Conceição.pdf>. Acesso em: 16 jul. 2014.

COSTA, Sergio (Coordenador). A saga da avicultura brasileira: como o Brasil se tornou o maior exportador mundial de carne de frango. Rio de Janeiro: UBABEF, 2011.

COTTA, Tadeu. Frangos de corte: criação, abate e comercialização. Viçosa: Ed. Aprenda Fácil, 2012.

GUJÃ̃ ALIMENTOS. Nossa história. Apresenta o histórico de fundação da empresa. Disponível em: $<$ http://gujao.com.br/v2/nossa-historia/>. Acesso em 05 mar. 2015.

INSTITUTO BRASILEIRO DE GEOGRAFIA E ESTATÍSTICA/GERÊNCIA DE PECUÁRIA IBGE/GEPEC. Proposta de reformulação da Pesquisa Pecuária Municipal: 2013. IBGE/GEPEC, 2013. Disponível em: http://www.ibge.gov.br/home/estatistica/ indicadores/prpa/Reformulacao_da_PPM_2013.pdf. Acesso em 01 mar. 2016.

PESQUISA PECUÁRIA MUNICIPAL - PPM. Efetivo dos rebanhos 31/12, por tipo de rebanho. Rio de Janeiro: IBGE, 2015. Disponível em: http://www.sidra.ibge.gov.br/bda/ tabela/listabl.asp?c=3939\&z=p\&o=28. Acesso em 10 jan. 2016.

PINAZZA, Luis Antônio; LUANDOS, Ivan Pupo. A revolução das aves. Agroanalysis, Instituto Brasileiro de Economia/Centro de estudos agrícolas, v. 20, n. 8, p.12 -38 ago. 2000

TAVARES, L. P.; RIBEIRO, K. C. S. Desenvolvimento da avicultura de corte brasileira e perspectivas frente à influenza aviária. Organizações Rurais \& Agroindustriais. Lavras: Universidade Federal de Lavras/Departamento de Administração e Economia, v. 9, n. 1, p. 79-88, 2007.

VOILÀ M.; TRICHES, D. A cadeia de carne de frango: uma análise dos mercados brasileiro e mundial de 2002 a 2010. Caxias do Sul: Universidade de Caxias do Sul - Instituto de Pesquisas Econômicas e Sociais. Texto para Discussão n. 44, jan. de 2013. 